\title{
Correlation between ultrasonographic, hysteroscopic and histopathological findings in patients with abnormal uterine bleeding
}

\author{
Binti R. Bhatiyani, Shrikant Dhumale*, Pandeeswari, Dolly Bashani
}

Department of Obstetrics and Gynecology, ESI PGIMSR, Mumbai, Maharashtra, India

Received: 31 May 2018

Accepted: 28 June 2018

\section{*Correspondence:}

Dr. Shrikant Dhumale,

E-mail: shriropra4211@gmail.com

Copyright: (C) the author(s), publisher and licensee Medip Academy. This is an open-access article distributed under the terms of the Creative Commons Attribution Non-Commercial License, which permits unrestricted non-commercial use, distribution, and reproduction in any medium, provided the original work is properly cited.

\begin{abstract}
Background: Menstrual disorders are common indication for medical visits among women of reproductive age and heavy menstrual bleeding affects up to $30 \%$ of women throughout their reproductive lifetime. This study aims at evaluating the different causes and, the clinical presentation of AUB and to compare the role of hysteroscopy, ultrasonography and histopathology in patients with AUB.

Methods: 100 women above 45 years of age, presenting with abnormal bleeding per vaginum were evaluated. All patients underwent transvaginal scan to note down the endometrial thickness and to rule out uterine and adnexal pathology. All the patients underwent diagnostic hysteroscopy, followed by a biopsy of the endometrium using a curette. The endometrium was sent to the pathologist. Findings of these diagnostic modalities then correlated.

Results: Incidence of AUB was present between the age groups of 45-49 years of age (66\%). The commonest presenting complaint in this series was menorrhagia or heavy menstrual bleeding $(60 \%)$. The finding of thickened endometrium as the most common abnormality on USG (44\%) and also on hysteroscopy (45\%). As per present study the sensitivity of hysteroscopy is $97.78 \%$ and specificity was $34.55 \%$, the negative predictive value of the test is $95 \%$. Conclusions: TVS may be the first line of investigation while evaluating the endometrium in a perimenopausal AUB. It helps to triage the patients into high risk or low risk. Endometrial thickness $>4 \mathrm{~mm}$ as per the present study needs further evaluation. Patients with endometrial thickness less than $4 \mathrm{~mm}$ can be reassured. Hysteroscopy is the gold standard in the diagnosis of focal pathology like sub mucous fibroid, polyps or anomalies. Histopathology probably is an indispensable tool specially to rule out premalignant and malignant conditions. Thus, all the modalities instead of being competitive to one another, are complimentary to each other. For complete evaluation of patient with AUB all the three modalities should be used together to come at exact diagnosis.
\end{abstract}

Keywords: Abnormal uterine bleeding, Hysteroscopy, Histopathology, Ultrasonography

\section{INTRODUCTION}

Abnormal uterine bleeding (AUB) refers to bleeding that is excessive or occurs outside of criteria of normal cyclic menstruation. AUB is described by a variety of terms and may be caused by number of gynecological conditions, systemic disorders, and medications. AUB was defined as 'bleeding from the uterine corpus that is abnormal in volume, regularity and/or timing that has been present for the majority of the last 6 months. ${ }^{1}$ AUB was redefined by Federation of International Gynaecology and Obstetrics (FIGO) in 2009 by the FIGO Menstrual Disorders Group (FMDG).,

Menstrual disorders are common indication for medical visits among women of reproductive age and heavy menstrual bleeding affects up to $30 \%$ of women throughout their reproductive lifetime. ${ }^{3}$ 
About one third of gynaecological consultations in routine OPD and nearly two-thirds of hysterectomies are because of abnormal uterine bleeding. This problem further rises in perimenopausal and postmenopausal women.

Normal menstrual cycle is a physiological phenomenon for a woman in which woman bleeds every month with gap of 21 to 35 days average being 28 days and for duration of 3-5 days and amount being 25-30 ml per day. Menses is a suspension of blood and tissue derived solids within mixture of serum and cervicovaginal fluid; the blood content of menses varies over the days of bleeding. ${ }^{4}$

Bleeding in any of the following situations is abnormal intermenstrual. Postcoital, bleeding in excess of quantity, frequency or duration more than normal, Postmenopausal. AUB could be due to wide range of conditions like, endometrial hyperplasia, pregnancy and related condition, fibroids, ectopic pregnancy, adenomyosis, polyp, infection of the uterus or cervix and many more.

Patients with AUB can present in different ways such as menorrhagia, metrorrhagia, menometrorrhagia, polymenorrhea, postmenopausal bleeding. Most common presentation being menorrhagia.

46 AUB can be evaluated using different methods; most common are ultrasound, endometrial biopsy and hysteroscopy. Since dilatation and curettage is a blind procedure, it will only scrape less than $50 \%$ of the endometrial cavity in $60 \%$ of the patients, so becomes less accurate than hysteroscopy in diagnosing structural pathology such as polyps, fibroids, intrauterine adhesions and congenital malformations. ${ }^{5}$ It has a cancer detection failure rate of $0.9 \% .^{6}$ With limited resources, in developing countries like India, it is the most commonly used method of assessing AUB. ${ }^{7}$

Transvaginal scan is also less accurate than hysteroscopy in diagnosing exact pathology, but it can give fair idea about structural abnormalities intrauterine pathology. ${ }^{8}$

Transvaginal sonography is preferred over uniform biopsy of postmenopausal women with vaginal bleeding because it is a less invasive procedure, generally painless, has no complications and may be more sensitive for detecting carcinoma than blind biopsy. ${ }^{9}$

\section{METHODS}

Women above 45 years of age, presenting with abnormal bleeding per vaginum from August 2015 to July 2017 were included in the study. The study was conducted after obtaining ethical clearance and after fulfilling the exclusion and inclusion criteria. Informed written consent was obtained from them. A detailed history was taken, and a thorough clinical examination was done. Complete blood count, bleeding time, clotting time, random Blood Sugar, urine analysis for protein, sugar and microscopy, HIV, HBsAg, VDRL, Blood grouping and Rh typing were done in all the patients. All patients underwent Transvaginal scan using $7.5 \mathrm{MHz}$ probe to note down the endometrial thickness and to rule out other uterine and adnexal pathology. Next all the patients underwent diagnostic hysteroscopy under short GA, using a $4 \mathrm{~mm}$ hysteroscope. The hysteroscopy findings were documented. This was followed by a biopsy of the endometrium using a curette. The hysteroscopy findings were classified as atrophic endometrium, proliferative (dull pink relatively thin), secretory (bright pink uniform), and hyperplastic (Fluffy thick obscuring the view), and other findings like sub mucous fibroid, polyps, local unhealthy areas suggestive of malignancy were noted. Histopathology findings of atrophic, hyperplasia, secretory, proliferative and malignancy of the endometrium were noted. The sensitivity, specificity, positive predictive value and negative predictive values of TVS and hysteroscopy in relation to histopathology were calculated. To study the correlation between the findings Kappa co efficient was calculated and declared as poor, fair, moderate, substantial, almost perfect and perfect depending on the Kappa value. Following this conclusion were drawn.

\section{Inclusion criteria}

- Women above 45 years of age with history of abnormal uterine bleeding.

\section{Exclusion criteria}

- Pregnancy

- $\quad$ IUCD

- Hormone producing ovarian tumours

- Endocrine disorders like hyper- or hypothyroidism, diabetes, adrenal disease, prolactin disorders

- Coagulation disorders

- Liver/renal diseases

- Known cervical or uterine malignancy

- On medications like steroids, neuroleptics, anticoagulants and cytotoxic agents.

\section{RESULTS}

In present study authors found that the maximum incidence of AUB was present between the age groups of 45-49 years of age $(66 \%)$.

Table 1: Distribution among the cases of -age.

\begin{tabular}{|c|c|c|}
\hline Age (years) & No. & Percentage \\
\hline 45 to 49 & 66 & 66.0 \\
\hline 50 to 54 & 21 & 21.0 \\
\hline 55 to 59 & 7 & 7.0 \\
\hline 60 to 65 & 6 & 6.0 \\
\hline Total & 100 & 100.0 \\
\hline
\end{tabular}


The commonest presenting complaint in this series was menorrhagia or heavy menstrual bleeding $(60 \%)$. Most of the patients coming to OPD usually seek medical attention within 6 months of menstrual complains (75\%). The finding of thickened endometrium as the most common abnormality on USG (44\%) and also on hysteroscopy (45\%). As per present study the sensitivity of hysteroscopy was $97.78 \%$ and specificity was $34.55 \%$, the negative predictive value of the test was $95 \%$ hence there was a fair correlation between the hysteroscopic findings and HPE report to find out true negative cases. In present study sensitivity of ultrasonography in diagnosing the cause of AUB was $84.44 \%$, specificity was $18.18 \%$, positive predictive value was $45.78 \%$ and negative predictive value is $58.82 \%$.

Table 2: Distribution among the cases of -chief complaints.

\begin{tabular}{|lll|}
\hline Chief complaints & No. & Percentage \\
\hline Heavy menstrual bleeding & 60 & 60.0 \\
\hline Postmenopausal bleeding & 12 & 12.0 \\
\hline Intermenstrual bleeding & 11 & 11.0 \\
\hline $\begin{array}{l}\text { Heavy and prolonged menstrual } \\
\text { bleeding }\end{array}$ & 10 & 10.0 \\
\hline Postcoital bleeding & 7 & 7.0 \\
\hline Total & 100 & 100.0 \\
\hline
\end{tabular}

Table 3: Distribution among the cases of duration of chief complaints.

\begin{tabular}{|c|c|c|}
\hline $\begin{array}{l}\text { Duration of chief } \\
\text { complaint (months) }\end{array}$ & No. & Percentage \\
\hline One & 13 & 13.0 \\
\hline 2 & 12 & 12.0 \\
\hline 3 & 10 & 10.0 \\
\hline 4 & 19 & 19.0 \\
\hline 5 & 5 & 5.0 \\
\hline 6 & 16 & 16.0 \\
\hline 8 & 5 & 5.0 \\
\hline 12 & 12 & 12.0 \\
\hline 18 & 1 & 1.0 \\
\hline 24 & 7 & 7.0 \\
\hline Total & 100 & 100.0 \\
\hline
\end{tabular}

In present study sensitivity of ultrasonography in diagnosing the cause of AUB was $84.44 \%$, specificity was $18.18 \%$, positive predictive value was $45.78 \%$ and negative predictive value is $58.82 \%$.

In the present study, by comparing the TVUS results against hysteroscopy authors found that hysteroscopy has significantly high sensitivity but comparable specificity with TVUS in diagnosing intrauterine pathology like endometrial polyp and submucous fibroid. Comparable sensitivity and specificity in diagnosing endometrial hyperplasia.
Table 4: Distribution among the cases ofcomorbidities.

\begin{tabular}{|c|c|c|}
\hline Comorbidities & No. & Percentage \\
\hline Hypertension & 9 & 9.0 \\
\hline Diabetes & 5 & 5.0 \\
\hline Hypertension and DM & 4 & 4.0 \\
\hline Tuberculosis & 3 & 3.0 \\
\hline Hypothyroid & 3 & 3.0 \\
\hline DM+Hyperthyroid & 1 & 1.0 \\
\hline Galactorrhea & 1 & 1.0 \\
\hline Hypothyroid+Tuberculosis & 1 & 1.0 \\
\hline Megaloblastic anaemia & 1 & 1.0 \\
\hline $\begin{array}{l}\text { Rheumatoid } \\
\text { Arthritis+DVT+Hypothyroid }\end{array}$ & 1 & 1.0 \\
\hline No comorbidity & 71 & 71.0 \\
\hline Total & 100 & 100.0 \\
\hline
\end{tabular}

Table 5: Distribution among the cases of-pathology in ultrasonography.

\begin{tabular}{|lll|}
\hline Pathology in & No. & Percentage \\
\hline ultrasonography & 44 & 44.0 \\
\hline Thickened endometrium & 17 & 17.0 \\
\hline Submucous fibroid & 13 & 13.0 \\
\hline Adenomyosis & 8 & 8.0 \\
\hline Endometrial polyp & 1 & 1.0 \\
\hline Endocervical polyp & 17 & 17.0 \\
\hline No abnormality detected & 100 & 100.0 \\
\hline Total & & \\
\hline
\end{tabular}

Table 6: Distribution among the cases ofhysteroscopic finding.

\begin{tabular}{|lll|}
\hline Hysteroscopic finding & No. & Percentage \\
\hline Thickened endometrium & 45 & 45.0 \\
\hline Endometrial polyp & 15 & 15.0 \\
\hline Atrophic endometrium & 12 & 12.0 \\
\hline Submucous fibroid & 7 & 7.0 \\
\hline Septate uterus & 1 & 1.0 \\
\hline No abnormality detected & 20 & 20.0 \\
\hline Total & 100 & 100.0 \\
\hline
\end{tabular}

Table 7: Distribution among the cases of- HPR report.

\begin{tabular}{|lll|}
\hline HIPE Report & No. & Percentage \\
\hline $\begin{array}{l}\text { Endometrial hyperplasia with } \\
\text { atypia }\end{array}$ & 2 & 2.0 \\
\hline Secretory phase endometrium & 39 & 39.0 \\
\hline $\begin{array}{l}\text { Proliferative phase } \\
\text { endometrium }\end{array}$ & 16 & 16.0 \\
\hline $\begin{array}{l}\text { Disordered proliferative } \\
\text { endometrium }\end{array}$ & 14 & 14.0 \\
\hline Endometrial polyp & 14 & 14.0 \\
\hline $\begin{array}{l}\text { Endometrial hyperplasia } \\
\text { without atypia }\end{array}$ & 14 & 14.0 \\
\hline Leiomyoma & 1 & 1.0 \\
\hline Total & 100 & 100.0 \\
\hline
\end{tabular}


Table 8: HPE report by hysteroscopic findings.

\begin{tabular}{|c|c|c|c|c|c|}
\hline \multirow{2}{*}{ Hysteroscopic finding } & & \multicolumn{2}{|c|}{ HPE Report } & \multirow{2}{*}{ Total } & \\
\hline & & Abnormal & Normal & & \\
\hline \multirow[t]{2}{*}{ Abnormal } & No. & 44 & 36 & 80 & \\
\hline & $\%$ & $55.00 \%$ & $45.00 \%$ & $100.00 \%$ & \\
\hline \multirow[t]{2}{*}{ Normal } & No. & 1 & 19 & 20 & \\
\hline & $\%$ & $5.00 \%$ & $95.00 \%$ & $100.00 \%$ & \\
\hline \multirow[t]{2}{*}{ Total } & No. & 45 & 55 & 100 & \\
\hline & $\%$ & $45.00 \%$ & $55.00 \%$ & $100.00 \%$ & \\
\hline Sensitivity & $97.78 \%$ & $88.23 \%$ & $99.94 \%$ & & \\
\hline Specificity & $34.55 \%$ & $22.24 \%$ & $48.58 \%$ & & \\
\hline Predictive value of positive test & $55.00 \%$ & $43.47 \%$ & $66.15 \%$ & & \\
\hline Predictive value of negative test & $95.00 \%$ & $75.13 \%$ & $99.87 \%$ & & \\
\hline Likelihood ratio of positive test & 1.4938 & 1.2267 & 1.8191 & & \\
\hline Likelihood ratio of negative test & 0.0643 & 0.0090 & 0.4622 & & \\
\hline \multirow[t]{2}{*}{ Youden's index } & 0.3232 & 0.1904 & 0.4561 & & \\
\hline & & Value & Approx. T & p-value & Agreement is- \\
\hline Measure of Agreement & Kappa & 0.302 & 4.020 & $5.8200 \mathrm{E}-05$ & Fair \\
\hline \multirow{2}{*}{ Pathology in ultrasonography } & & \multicolumn{2}{|l|}{ HPE Report } & \multirow{2}{*}{ Total } & \\
\hline & & Abnormal & Normal & & \\
\hline \multirow[t]{2}{*}{ Abnormal } & No. & 38 & 45 & 83 & \\
\hline & $\%$ & $45.80 \%$ & $54.20 \%$ & $100.00 \%$ & \\
\hline \multirow[t]{2}{*}{ Normal } & No. & 7 & 10 & 17 & \\
\hline & $\%$ & $41.20 \%$ & $58.80 \%$ & $100.00 \%$ & \\
\hline \multirow{2}{*}{ Total } & No. & 45 & 55 & 100 & \\
\hline & $\%$ & $45.00 \%$ & $55.00 \%$ & $100.00 \%$ & \\
\hline Sensitivity & $84.44 \%$ & $70.54 \%$ & $93.51 \%$ & & \\
\hline Specificity & $18.18 \%$ & $9.08 \%$ & $30.90 \%$ & & \\
\hline Predictive value of positive test & $45.78 \%$ & $34.79 \%$ & $57.08 \%$ & & \\
\hline Predictive value of negative test & $58.82 \%$ & $32.92 \%$ & $81.56 \%$ & & \\
\hline Likelihood ratio of positive test & 1.0321 & 0.8649 & 1.2317 & & \\
\hline Likelihood ratio of negative test & 0.8556 & 0.3542 & 2.0665 & & \\
\hline \multirow[t]{2}{*}{ Youden's index } & 0.0263 & -0.1207 & 0.1732 & & \\
\hline & & Value & Approx. T & p-value & Agreement is- \\
\hline Measure of Agreement & Kappa & 0.024 & 0.348 & 0.728 & Slight \\
\hline
\end{tabular}

Table 8: Association among the cases between pathology in ultrasonography * HPE report.

\begin{tabular}{|c|c|c|c|c|c|}
\hline \multirow{2}{*}{ Pathology in ultrasonography } & & \multicolumn{2}{|c|}{ HPE Report } & \multirow{2}{*}{ Total } & \\
\hline & & Abnormal & Normal & & \\
\hline \multirow[t]{2}{*}{ Abnormal } & No. & 38 & 45 & 83 & \\
\hline & $\%$ & $45.80 \%$ & $54.20 \%$ & $100.00 \%$ & \\
\hline \multirow[t]{2}{*}{ Normal } & No. & 7 & 10 & 17 & \\
\hline & $\%$ & $41.20 \%$ & $58.80 \%$ & $100.00 \%$ & \\
\hline \multirow[t]{2}{*}{ Total } & No. & 45 & 55 & 100 & \\
\hline & $\%$ & $45.00 \%$ & $55.00 \%$ & $100.00 \%$ & \\
\hline Sensitivity & $84.44 \%$ & $70.54 \%$ & $93.51 \%$ & & \\
\hline Specificity & $18.18 \%$ & $9.08 \%$ & $30.90 \%$ & & \\
\hline Predictive value of positive test & $45.78 \%$ & $34.79 \%$ & $57.08 \%$ & & \\
\hline Predictive value of negative test & $58.82 \%$ & $32.92 \%$ & $81.56 \%$ & & \\
\hline Likelihood ratio of positive test & 1.0321 & 0.8649 & 1.2317 & & \\
\hline Likelihood ratio of negative test & 0.8556 & 0.3542 & 2.0665 & & \\
\hline \multirow[t]{2}{*}{ Youden's index } & 0.0263 & -0.1207 & 0.1732 & & \\
\hline & & Value & Approx. T & p-value & Agreement is- \\
\hline Measure of agreement & Kappa & 0.024 & 0.348 & 0.728 & Slight \\
\hline
\end{tabular}


Structural abnormalities of endometrial cavity such as polyps, submucous fibroid can be better diagnosed with hysteroscopy. Likelihood ratio of positive test with hysteroscopy was 1.4938 and it was more than that of ultrasonography (1.0321) again proving that hysteroscopy was better investigation as compared to ultrasonography as there is more possibility of having abnormality on HPE report if hysteroscopy was showing some abnormality.

\section{DISCUSSION}

Clinical management of AUB aims at obtaining an accurate diagnosis and charting out correct line of management. On USG the uterine contour and morphology of ovary can be found but it fails to provide adequate information regarding the pathology of the endometrium. Hysteroscopy in this new era is increasingly becoming a valuable investigation for the evaluation of AUB.

In this study we evaluated 100 patients of AUB above the age of 45 who presented to OPD. In present study authors found that the maximum incidence of AUB was present between the age groups of 45-49 years of age (66\%). In a study conducted by Patil et al a total of 100 patients of age more than 18 years with AUB were evaluated and found that Abnormal uterine bleeding was most prevalent among women of two age groups, 26-30 years and 41-45 years $(22 \%) .{ }^{10}$ In another study conducted by Kathuria et al evaluating 50 patients between age group of 20-60 years and found to maximum incidence between the age group of 30-39 years (44\%). ${ }^{11}$ Present study showed a different prevalence profile than the above studies as we have considered patients above 45 years of age as study population.

The commonest presenting complaint was menorrhagia or heavy menstrual bleeding $(60 \%)$ followed by postmenopausal bleeding (12\%) followed by intermenstrual bleeding $(11 \%)$ and heavy and prolonged menstrual bleeding $(10 \%)$ in that order. This was in consistence with many other studies like in a study by Shyam et al, the most common symptom in patients with abnormal uterine bleeding was menorrhagia $(40 \%)$, metrorrhagia $(18 \%)$, menometrorrhagia $(14 \%)$, and polymenorrhea $(14 \%) .{ }^{12}$ In Kathuria et al series the commonest presenting complaint was menorrhagia $46 \%$, followed by polymenorrhea $(30 \%)$ and metrorrhagia $(18 \%)$ and postmenopausal bleeding in $6 \% .^{11}$ Shrinivas concluded that $46 \%$ of patients presented with heavy menstrual bleeding, $34 \%$ had increased cycle frequency (Past terminology of polymenorrhea) and $20 \%$ of them had presented with continuous bleeding. ${ }^{13}$

Most of the patients coming to OPD usually seek medical attention within 6 months of menstrual complains (75\%). In study by Kathuria et al found that most of the patients seek medical attention after suffering for 3-6 months time $(50 \%) .{ }^{11}$ In another study conducted by Kulkarni $\mathrm{S}$ et al, it was found that $54 \%$ patients presents within 6 months of complaints. ${ }^{14}$ Patients do not seek medical attention early because menstrual complaints are usually neglected in our country and also may be because females feel awkward discussing these complaints and most of the time they are not aware that this can cause serious problem in future.

Out of 100 patients in present study most of them (71\%) presented with isolated complaints of menstrual abnormality and had no other associated medical comorbidities while the remaining patients had some or the other associated morbid conditions. Among these hypertensions was seen in $9 \%$ patients, diabetics in $5 \%$ patients and hypothyroidism in $3 \%$ patients and tuberculosis in $3 \%$. In a study conducted by Patil et al $14 \%$ of the patients were hypertensive, $6 \%$ had history of tuberculosis, $5 \%$ were diabetic and $5 \%$ of the patients were having sickle cell disease. ${ }^{10}$

Ultrasonography being easily available and more feasible as compared to hysteroscopy, done first. In present study ultrasonography showed some abnormality in $83 \%$ of the patients while in $17 \%$ patients it was normal. Among the detected abnormalities, thickened endometrium was the most common (44\%) followed by fibroid in $17 \%$, adenomyosis in $13 \%$, endometrial polyp $8 \%$ and endocervical polyp in $1 \%$. This finding of thickened endometrium as the most common abnormality on USG is in concordance with many other studies.

In a study done by Karlsson et al, they found that 39 out of 51 patients in their studies had thickened endometrium as abnormal finding on USG. ${ }^{15}$ In a study by Patil S, et al. endometrial hyperplasia (15\%) was the most commonly detected pathology, followed by fibroid uterus (13\%), on ultrasonography. ${ }^{10}$ In a study by El-lhayat $\mathrm{W}$ et al it was $32 \% .{ }^{16}$ In a study by Sharma et al $(66 \%)$ had abnormal finding in which most common finding of hyperplastic endometrium. $^{13}$ USG as a diagnostic modality overestimates the actual number of abnormalities as found in present study.

Patients with either abnormal or normal findings on USG were then evaluated with hysteroscopy followed by endometrial biopsy sampling in the same setting. Hysteroscopy provides direct visualization of the endometrial cavity. In present study, out of 100 patients, $80 \%$ patients were found to have abnormal findings (thickened endometrium, polyp, fibroid, scarring, atrophy, septum) rest $20 \%$ found to have no detectable cause of AUB on hysteroscopy. Out of these $80 \%$ abnormal findings, thickened endometrium was found in $45 \%$ patients which was similar to USG findings. This was similar to many other studies. In present study, the most common finding was thickened endometrium (45\%), followed by endometrial polyp 15\%, atrophic endometrium $12 \%$, submucous fibroid $7 \%$ and an incidental finding of septate uterus in one patient. On contrast in a study done by El-Ihyat et al, on 
hysteroscopy the commonest lesion diagnosed was endometrial polyp which was found in $28 \%$ of cases, while endometrial hyperplasia found only in $20 \% .^{16}$

In present study endometrial sampling was done for all 100 patients in same setting when patient was posted for Dilatation and curettage with hysteroscopy. On HPE report the most common histopathological finding was Secretory phase endometrium in 39 patients followed by proliferative phase endometrium in 16 patients. Finding of disordered proliferative endometrium was noted in 14 patients, endometrial polyp in 14 patients, endometrial hyperplasia without atypia in 14 patients, endometrial hyperplasia with atypia in 2 patients and leiomyoma in 1 patient. In present study histopathology report revealed abnormality in $43 \%$ patients while rest $57 \%$ patients were found to have normal histopathological report. This almost similar to study done by Kathuria $\mathrm{R}$ et al where $40 \%$ patients have some or the other abnormality while $60 \%$ patients have normal HPE report. ${ }^{11}$ In a study by Patil $\mathrm{S}$ et al they found proliferative phase endometrium as most common finding which is contrary to present study finding of secretory endometrium as most common histopathological report. ${ }^{10}$

Among the 100 patients that were evaluated with hysteroscopy $80 \%$ of the patients found to have abnormality whereas $20 \%$ patients had normal hysteroscopic findings. Among the patients with abnormal hysteroscopic findings 44 cases (55\%) were also have abnormality on HPE report while 36 cases (45\%) were normal on HPE report. Among the 20 hysteroscopicaly normal patients 19 cases $(95 \%)$ had normal HPE report, and only 1 case $(5 \%)$ found to have abnormality.

As per present study the sensitivity of hysteroscopy was $97.78 \%$ and specificity were $34.55 \%$, the negative predictive value of the test is $95 \%$ hence there is a fair correlation between the hysteroscopic findings and HPE report to find out true negative cases. Because of high sensitivity $(97.78 \%)$ of hysteroscopy, there were higher chances to detect cases with true abnormality but due to low specificity the test was not appropriate to diagnose cases with no abnormality and hence HPE is needed to come to confirm the diagnosis. Though HPE will be required for final diagnosis but there is fair correlation between hysteroscopic findings and actual HPE report and hence hysteroscopy can be used as initial investigation while evaluating the patients with AUB.

Structural abnormalities of endometrial cavity such as polyps, submucous fibroid can be better diagnosed with hysteroscopy. Likelyhood ratio of positive test with hysteroscopy was 1.4938 and it was more than that of ultrasonography (1.0321) again proving that hysteroscopy was better investigation as compared to ultrasonography as there is more possibility of having abnormality on HPE report if hysteroscopy is showing some abnormality.
Among the 100 patients that were evaluated with ultrasonography $83 \%$ of the patients found to have abnormality whereas $17 \%$ patients had normal ultrasonography findings. Amongst the patients with abnormal ultrasonography findings 38 cases $(45.80 \%)$ were also having abnormality on HPE report while 45 cases $(54.20 \%)$ were normal on HPE report.

Among the 17 ultrasonographically normal patients 10 cases $(58.80 \%)$ had normal HPE report, and 7 cases $(41.20 \%)$ cases found to have abnormality. In present study sensitivity of ultrasonography in diagnosing the cause of AUB is $84.44 \%$, specificity is $18.18 \%$, positive predictive value is $45.78 \%$ and negative predictive value is $58.82 \%$.

While comparing the findings of ultrasonography and hysteroscopy, among the 100 patients, on ultrasonography 83 patients found to have abnormality whereas 17 patients had normal ultrasonography findings. Amongst the patients with abnormal ultrasonography findings 65 cases $(78.30 \%)$ were also having abnormality on hysteroscopy. Among the 17 patients with normal ultrasonographic findings only 2 patients $(11.80 \%)$ were also normal on hysteroscopy. This means that it is possible to over diagnose an abnormality on ultrasonography.

The sensitivity, specificity and negative predictive value, all the modalities of good screening test are higher with hysteroscopy as compared to USG. Hence it was not possible to diagnose true negatives or positives as accurately on ultrasonography as hysteroscopy, when the actual histopathological correlation is kept in mind. This was further confirmed by the later observations and analysis between USG and hysteroscopy where it shows that USG overestimates the disease burden probably due to interobserver variability. Though the experience of the surgeon doing the hysteroscopy is also a factor to be considered, but usually it is negated by the direct observation and cross confirmation with the experienced surgeons during procedure. Also, the hysteroscopic findings pathognomonic of septate uterus, small submucous fibroid etc. are easy to be missed on USG but can be picked up in hysteroscopy with ease.

Of the 100 patients in present study, $66 \%$ were in the age group of 45-49 years of age, followed by $21 \%$ between age group of 50-54 years, $7 \%$ between 55-59 years and $6 \%$ between $60-65$ years. $60 \%$ of them presented with the complaints of heavy menstrual bleeding. The transvaginal scan assessment showed that 3 patients showed an endometrial thickness of less than $4 \mathrm{~mm}, 60$ patients showed an endometrial thickness between 4-8 mm, 25 between $8-12 \mathrm{~mm}, 9$ of them between $12-16 \mathrm{~mm}, 3$ of them $>16 \mathrm{~mm}$.

Diagnostic hysteroscopy revealed the appearance of thickened endometrium in $45 \%$, atrophic in $12 \%$. No case of endometrial carcinoma was diagnosed. Focal lesions 
like sub mucous fibroid was diagnosed in $7 \%$, Polyp in $15 \%$ and a septate uterus was noted in $1 \%$ cases. Histopathology reports showed proliferative endometrium in 16 patients, secretory in 39 patients, endometrial polyp in 14 and disorder proliferative endometrium in 14. Incidence of hyperplasia with atypia was $2 \%$ and $14 \%$ without atypia. Diagnostic value of hysteroscopy in comparison to histopathology gave an average sensitivity and specificity of $97.78 \%$ and $34.55 \%$ respectively, which is different for different findings on histopathology report.

Using kappa coefficient an agreement test was done between hysteroscopy and histopathology and again between TVS and histopathology. TVS showed a moderate agreement with histopathology for proliferative and secretory endometrium whereas the agreement was fair for hyperplastic endometrium but was poor for polyp. Hysteroscopy showed a substantial agreement for proliferative, secretory and hyperplastic endometrium and almost perfect agreement for focal lesions like polyp. For focal lesions TVS showed a low sensitivity which is in accordance with the report by Shrinivas $\mathrm{K}$ et al, who concluded that TVS was a preferred modality for endometrial thickness but not sensitive enough to rule out pathology. ${ }^{14}$

Pyari JS et al, too have concluded that hysteroscopy has a better sensitivity and specificity compared to TVS. ${ }^{12}$ Focal abnormalities were detected in the present study in a small number in contrast to other studies. This was probably due to the fact that the age group considered here is only perimenopausal whereas other studies have included women in reproductive age group, which could explain this.

\section{ACKNOWLEDGMENTS}

Authors would like to thank Dr Meenakshi Mathur for her support and encouragement.

Funding: No funding sources

Conflict of interest: None declared

Ethical approval: The study was approved by the Institutional Ethics Committee

\section{REFERENCES}

1. Munro MG, Critchley HO, Fraser IS. The FIGO classification of causes of abnormal uterine bleeding. Int J Gynecol Obstet. 2011;113(1):1-2.

2. Fraser IS, Critchley HO, Broder M, Munro MG. The FIGO recommendations on terminologies and definitions for normal and abnormal uterine bleeding. In Seminars in Reprod Med. 2011;29:(5):383-90.

3. Market Opinion and Research International (MORI). Women's health in 1990. (Research study conducted on behalf of Parke-Davis Laboratories). London: MORI; 1990.
4. Paula J, Berek AH, Novak's Gynaecology: benign diseases of female reproductive tract, $15^{\text {th }}$ ed. Philadelphia: Wolter Kluwer India Pvt Ltd; 2012:404.

5. Stock RJ, Kanbour A. Prehysterectomy curettage. Obstet. 1975;45(5):537-41.

6. William J. Butler, David E. Carnovale. Normal and abnormal uterine bleeding. In: Chapter 26, Telinde's operative gynaecology $10^{\text {th }}$ ed. John A Rock, Howard W. JonesIII (eds). New Delhi: Wolters Kluwer health and Lippincott Williams and Wilkins 2009:585-605.

7. Krampl E, Bourne T, Hurlen-Solbakken H, Istre O. Transvaginal ultrasonography sonohysterography and operative hysteroscopy for the evaluation of abnormal uterine bleeding. Acta Obstet Gynecol Scand. 2001;80(7):616-22.

8. Pasqualotto EB, Margossian H, Price LL, Bradley LD. Accuracy of preoperative diagnostic tools and outcome of hysteroscopic management of menstrual dysfunction. J Am Assoc Gynecol Laparoscopists. 2000;7(2):201-9.

9. Erdem M, Bilgin U, Bozkurt N, Erdem A. Comparison of transvaginal ultrasonography and saline infusion sonohysterography in evaluating the endometrial cavity in pre-and postmenopausal women with abnormal uterine bleeding. Menopause. 2007;14(5):846-52.

10. Patil SG, Bhute SB, Inamdar SA, Acharya NS, Shrivastava DS. Role of diagnostic hysteroscopy in abnormal uterine bleeding and its histopathologic correlation. J Gynecol Endoscop Surg. 2009;1(2):98.

11. Kathuria R, Bhatnagar BE. Correlation between D and C, USG and hysteroscopy findings in diagnosing a cause for abnormal uterine bleeding. Indian $\mathrm{J}$ Clin Practice. 2014;25(5):466-70.

12. Pyari JS, Rekha S, Srivastava PK, Goel M, Pandey M. A comparative diagnostic evaluation of hysteroscopy, transvaginal ultrasonography and histopathological examination in cases of abnormal uterine bleeding. $\mathbf{J}$ Obstet Gynecol India. 2006;56(3):240-3.

13. Sharma J, Tiwari S. Hysteroscopy in Abnormal Uterine Bleeding vs Ultrasonography and Histopathology Report in Perimenopausal and Postmenopausal Women. J Nepal Med Assoc. 2016 1;55(203).

14. Srinivas K, Kulkarni S Comparison of Efficacy of TVS and Hysteroscopy with Histopathology of the Endometrium in Evaluating Perimenopausal AUB (O). MOJ Women's Health. 2017;4(6):00104.

15. Karlsson B, Granberg S, Hellberg P, Wikland M. Comparative study of transvaginal sonography and hysteroscopy for the detection of pathologic endometrial lesions in women with postmenopausal bleeding. J Ultrasound Med. 1994;13(10):757-62.

16. El-khayatW, Sleet ME, Mahdi EY. Comparative study of transvaginal sonography and hysteroscopy for the detection of pathological endometrial lesions in women with perimenopausal bleeding. Middle East Fertil Soc J. 2011;16(1):77-82.

Cite this article as: Bhatiyani BR, Dhumale $S$, Pandeeswari, Bashani D. Correlation between ultrasonographic, hysteroscopic and histopathological findings in patients with abnormal uterine bleeding. Int J Reprod Contracept Obstet Gynecol 2018;7:3250-6. 